2008, 112, 5771-5773

Published on Web 06/05/2008

\title{
Simultaneous Tracking of Sulfur Species in the Oxidation of Thiourea by Hydrogen Peroxide
}

\author{
Qingyu Gao, ${ }^{\dagger, \ddagger}$ Guangping Wang, ${ }^{\dagger}$ Yanyan Sun, ${ }^{\dagger}$ and Irving R. Epstein*,", \\ College of Chemical Engineering, China University of Mining and Technology, \\ Xuzhou 221008, People's Republic of China, and Department of Chemistry and Volen Center for Complex \\ Systems, MS 015, Brandeis University, Waltham, Massachusetts 02454-9110
}

Received: January 15, 2008; Revised Manuscript Received: May 12, 2008

\begin{abstract}
We employ reversed-phase ion-pair high-performance liquid chromatography to quantitatively characterize the oxidation kinetics of thiourea oxidation by hydrogen peroxide. The HPLC technique makes it possible to monitor the concentrations of a variety of sulfur-containing species with different oxidation states and to elucidate the relative phase relations among them. The experimental results are in good agreement with simulations from an 8-step reaction mechanism.
\end{abstract}

Oxidation reactions of sulfur(-II) compounds such as thiourea (TU) can be quite complex, yielding species with oxidation states ranging from -1 to $+6 .^{1-4}$ Researchers have investigated the dynamics of these reactions from several perspectives: First, the mechanism of the nonlinear reaction between various oxidants and $\mathrm{TU}$ is of considerable interest for explaining such exotic phenomena as oscillations, chaos and spatiotemporal patterning seen in such systems. ${ }^{5-8}$ Secondly, the physiological effects of thiourea oxides have attracted scientists to explore the biofunction of these sulfur species. ${ }^{9,10}$ Finally, sulfur abatement is a key technology in alleviating environmental pollution. ${ }^{4,11}$ To tackle the above challenges, understanding the basic sulfur chemistry, i.e., the kinetics and mechanism of the changes of sulfur oxidation state, is essential. A major obstacle is the difficulty of tracking the different oxidation states of sulfur during the reaction. Standard methods of chemical analysis, which typically involve multiple steps and intensive experimental efforts, generally fail for most intermediates in these systems. UV-visible spectroscopy cannot quantify the sulfur intermediates, because their absorption spectra overlap.

Thiourea $\left(\lambda_{\max }=196 \mathrm{~nm}\right.$ and $236 \mathrm{~nm}, \varepsilon=11273$ and 11048 $\mathrm{M}^{-1} \mathrm{~cm}^{-1}$ ), is a typical sulfur(-II) compound that is widely used in industrial production. Its oxidation involves the formation of such reagents as formamidine disulfide $\left(\mathrm{TU}_{2}, \lambda_{\max }=\right.$ $\left.218 \mathrm{~nm}, \varepsilon=21523 \mathrm{M}^{-1} \mathrm{~cm}^{-1}\right)$, thiourea dioxide $\left(\mathrm{TUO}_{2}, \lambda_{\max }\right.$ $\left.=269 \mathrm{~nm}, \varepsilon=489 \mathrm{M}^{-1} \mathrm{~cm}^{-1}\right)$, thiourea trioxide $\left(\mathrm{TUO}_{3}, \lambda_{\max }\right.$ $\left.=202 \mathrm{~nm}, \varepsilon=7295 \mathrm{M}^{-1} \mathrm{~cm}^{-1}\right)$, sulfite $\left(\lambda_{\max }=205 \mathrm{~nm}, \varepsilon=\right.$ $3548 \mathrm{M}^{-1} \mathrm{~cm}^{-1}$ ) and sulfate. The overlap of the UV-vis absorption spectra prevents simultaneous detection of these intermediates. Using high-performance liquid chromatography (HPLC), Grigorova and Wright ${ }^{12}$ separated thiourea, formamidine disulfide and cyanamide from a hydrogen peroxide-thiourea reactive mixture. In this report, we describe a new approach for directly tracking the evolution of multiple sulfur species and performing kinetic analysis.

\footnotetext{
* Corresponding author. E-mail: epstein @ brandeis.edu.

China University of Mining and Technology.

* Brandeis University.
}

We employ reversed-phase ion-pair high-performance liquid chromatography to quantitatively characterize the oxidation kinetics of TU oxidation by hydrogen peroxide. Indeed, the capability to monitor simultaneously the time evolution of multiple sulfur species allows us not only to study the reaction kinetics but also to characterize the relative phase relations of the different species. Our results demonstrate that HPLC is a unique and effective means for the simultaneous and direct determination of sulfur species during a reaction. The chromatographic system used in this study comprises a Model G1379A pump with four pistons (Agilent 1100), a Model 7725 injection-valve equipped with a $20-\mu \mathrm{L}$ sample loop (Rneodyne), a Phenomenex Ginimi C18 separation column $(5.0 \mu \mathrm{m}, 46 \mu \mathrm{m}$ $\times 250 \mathrm{~mm}$ ), and a Model G1365B MWD UV-detector. The mobile phase (eluent) was prepared with the low UV chromatographic reagents methanol and $2.5 \mathrm{mM}$ tetrabutylammonium hydroxide $(\mathrm{TBAOH})$ by mixing the two solutions in the volume ratio 5:95. Water used in this study was distilled and then deionized with a Milli-Q system. An ultrasonic bath was used for degassing the sample. The total injection volume was kept constant at $10 \mu \mathrm{L}$. Thiourea stock solution was prepared daily by dissolving analytical grade $\mathrm{CS}\left(\mathrm{NH}_{2}\right)_{2}$ (Aldrich, purity $>99 \%$ ) in deionized water. Hydrogen peroxide (Sinopharm Chemical Reagent Co., 30\%) solution was titrated with standard potassium permanganate solution. Formamidine disulfide (Aldrich, purity $>97 \%$ ) and formamidine sulfinic acid (Fluka, purity $>98 \%$ ) were used as the standard compounds to characterize the reaction products. Formamidine sulfonic acid was prepared according to the literature. ${ }^{13}$ The buffer $\mathrm{pH}$ was controlled with hydrochloric acid. The oxidation of thiourea by hydrogen peroxide was carried out in a single cell reactor thermostated with a circulating water bath. Before and after the reaction there was no obvious change in the $\mathrm{pH}$ of the reaction mixture. All solutions were filtered through a $0.45 \mu \mathrm{m}$ filter membrane and were degassed prior to use. The $\mathrm{pH}$ of the mobile phase was kept the same as that of the reaction liquid.

With $[\mathrm{TU}]_{0}=6.2 \times 10^{-4} \mathrm{M}$ and $\left[\mathrm{H}_{2} \mathrm{O}_{2}\right]_{0} /[\mathrm{TU}]_{0}=19$, species such as $\mathrm{H}_{2} \mathrm{O}_{2}, \mathrm{TU}, \mathrm{TU}_{2}, \mathrm{TUO}_{2}$ and $\mathrm{TUO}_{3}$ can be detected by 

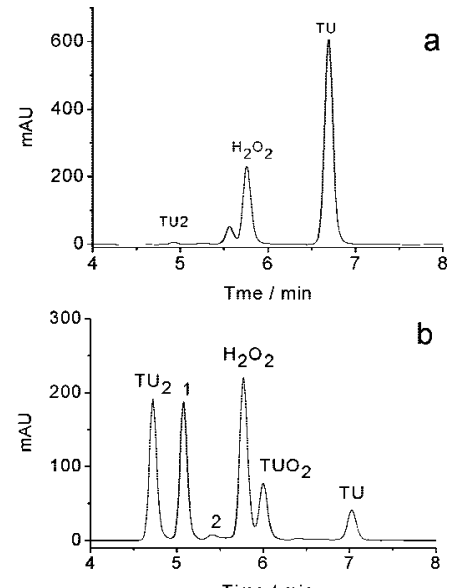

b
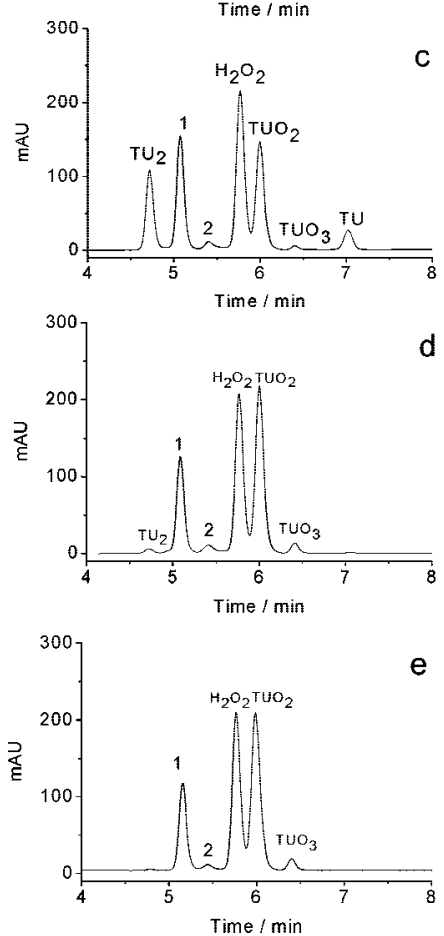

Figure 1. HPLC chromatograms of the hydrogen peroxide-thiourea system. $\left[\mathrm{H}_{2} \mathrm{O}_{2}\right]_{0}=1.18 \times 10^{-2} \mathrm{M},[\mathrm{TU}]_{0}=6.2 \times 10^{-4} \mathrm{M} ; \mathrm{pH}=$ 1.50; sampling time $=2.00 \mathrm{~min}(\mathrm{a}), 86.00 \mathrm{~min}$ (b), $197.00 \mathrm{~min}$ (c), $625.00 \mathrm{~min}(\mathrm{~d})$ and $1020.00 \mathrm{~min}(\mathrm{e})$; flow rate of mobile phase $=0.50$ $\min / \min , T=25^{\circ} \mathrm{C}$.

comparing the HPLC spectrum to HPLC standards of the individual species at the $\mathrm{pH}$ of the experiment, as shown for $\mathrm{pH} 1.50$ in Figure 1. When a sample was taken $2.0 \mathrm{~min}$ after the reaction started, $\mathrm{H}_{2} \mathrm{O}_{2}$ and TU were observed at different retention times. Figure $1 \mathrm{~b}$ shows two unknown species (retention time $=5.10 \mathrm{~min}$ and $5.40 \mathrm{~min}$ ), in addition to $\mathrm{H}_{2} \mathrm{O}_{2}, \mathrm{TU}, \mathrm{TU}_{2}$ and $\mathrm{TUO}_{2}$, at a sampling time of $86.00 \mathrm{~min}$. $\mathrm{TUO}_{3}$ was clearly observed at $197.00 \mathrm{~min}$. At much later sampling times, such as $625.0 \mathrm{~min}$ and $1020.0 \mathrm{~min}, \mathrm{TU}$ and $\mathrm{TU}_{2}$, respectively, were consumed. Ultimately, all sulfur species are oxidized to sulfate.

We attempted to identify the two unknown species 1 and 2 (retention times ca. 5.10 and $5.40 \mathrm{~min}$, respectively) in Figure 1 by investigating the hydrolysis of $\mathrm{TU}_{2}$, as shown in Figure $2 \mathrm{a}-\mathrm{c}$. Besides $\mathrm{TU}_{2}$ and $\mathrm{TU}$, two peaks consistent with species 1 and 2, also appeared. Neither retention time agrees with that of the otherwise plausible $\mathrm{NH}_{2} \mathrm{CN}$. By HPLC-MS, we find mass to charge ratios of 91.28 and 116.38 , respectively, the former of which is compatible with the possible intermediate sulfenyl acid, but we are unable to definitively identify species
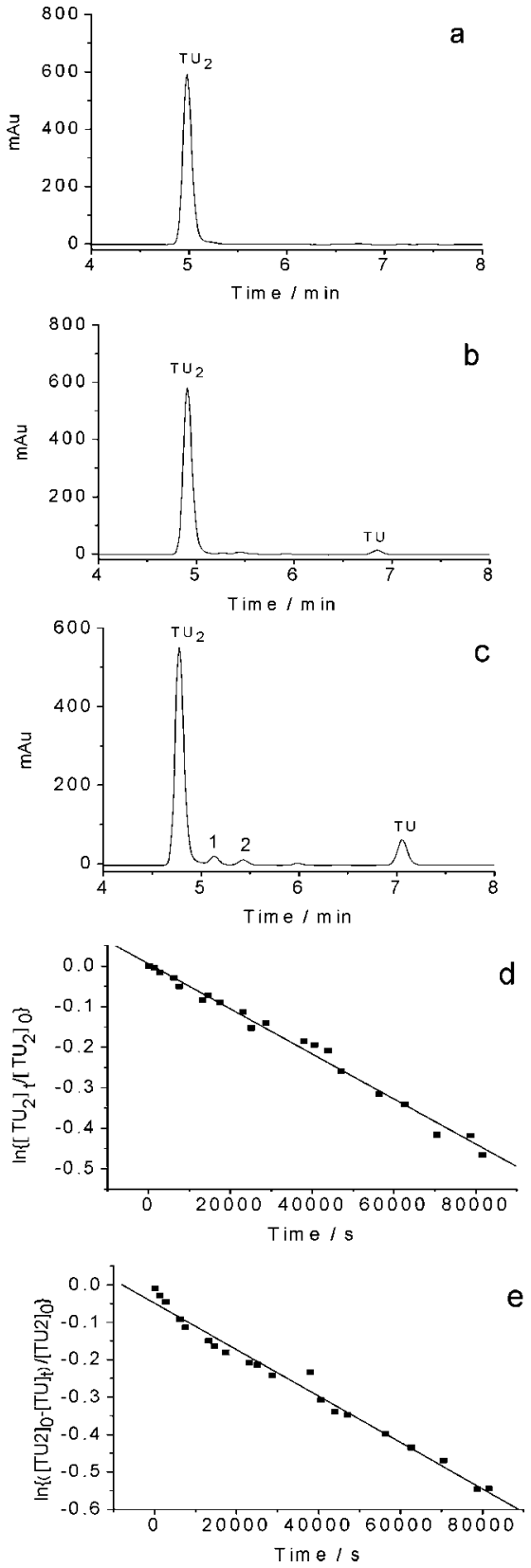

Figure 2. HPLC chromatograms and plots of concentration vs time during hydrolysis of formamidine disulfide. $\left[\mathrm{TU}_{2}\right]_{0}=6.0 \times 10^{-4} \mathrm{M}$; $\mathrm{pH}=1.50$; sampling time $=2.00 \mathrm{~min}(\mathrm{a}), 22.00 \mathrm{~min}(\mathrm{~b})$ and 125.00 min (c). Integrated rate plots of the first-order rate equation: $\ln \left\{\left[\mathrm{TU}_{2}\right]_{t} /\right.$ $\left.\left[\mathrm{TU}_{2}\right]_{0}\right\}$ vs $t(\mathrm{~d}) ; \ln \left\{\left(\left[\mathrm{TU}_{2}\right]_{0}-[\mathrm{TU}]_{t}\right) /\left[\mathrm{TU}_{2}\right]_{0}\right\}$ vs $t(\mathrm{e})$; flow rate of mobile phase $=0.50 \mathrm{~min} / \mathrm{min}, T=25^{\circ} \mathrm{C}$.

1 and 2. In Figure 2d,e, we confirm that the hydrolysis reaction produces one $\mathrm{TU}$ molecule for every $\mathrm{TU}_{2}$ molecule. The plots show $\ln \left\{\left[\mathrm{TU}_{2}\right]_{t} /\left[\mathrm{TU}_{2}\right]_{0}\right\}$ (Figure $2 \mathrm{~d}$ ) and $\ln \left\{\left(\left[\mathrm{TU}_{2}\right]_{0}-[\mathrm{TU}]_{t}\right) /\right.$ $\left.\left[\mathrm{TU}_{2}\right]_{0}\right\}$ vs $t$ (Fig. 2e). Both are straight lines with almost same slope $\left(5.56 \times 10^{-6} \mathrm{~s}^{-1}\right.$ and $\left.5.79 \times 10^{-6} \mathrm{~s}^{-1}\right)$. We take the average rate constant of the first-order hydrolysis reaction as $5.67 \times 10^{-6} \mathrm{~s}^{-1}$.

For the kinetic analysis, time series of concentrations of several reactive species were obtained by comparing the integrated peak area or peak height with a standard working curve. The evolution of those species illustrates the sequence of the oxidation processes. A typical time series, at the same experimental conditions as Figure 1, is shown in Figure 3. The concentration of $\mathrm{TU}_{2}$, which is produced through oxidation of $\mathrm{TU}$ by $\mathrm{H}_{2} \mathrm{O}_{2}$, rises at first, then drops. At the peak of $\left[\mathrm{TU}_{2}\right]$, the 
TABLE 1: Reaction Mechanism and Rate Constants for the $\mathrm{H}_{2} \mathrm{O}_{2}-\mathrm{TU}$ System at $\mathrm{pH}=1.50$

\begin{tabular}{|c|c|c|}
\hline no. & reaction & rate constants \\
\hline 1 & $\mathrm{H}_{2} \mathrm{O}_{2}+\mathrm{SC}\left(\mathrm{NH}_{2}\right)_{2} \rightarrow \mathrm{HOSC}(\mathrm{NH}) \mathrm{NH}_{2}+\mathrm{H}_{2} \mathrm{O}$ & $\begin{array}{l}r_{1}=k_{1}\left[\mathrm{H}_{2} \mathrm{O}_{2}\right]\left[\mathrm{SC}\left(\mathrm{NH}_{2}\right)_{2}\right] \\
k_{1}=0.115 \mathrm{M}^{-1} \mathrm{~s}^{-1}\end{array}$ \\
\hline 2 & $\mathrm{HOSC}(\mathrm{NH}) \mathrm{NH}_{2}+\mathrm{SC}\left(\mathrm{NH}_{2}\right)_{2} \rightarrow \mathrm{NH}_{2}(\mathrm{NH}) \mathrm{CSSC}(\mathrm{NH}) \mathrm{NH}_{2}+\mathrm{H}_{2} \mathrm{O}$ & $\begin{array}{l}r_{2}=k_{2}\left[\mathrm{HOSC}(\mathrm{NH}) \mathrm{NH}_{2}\right]\left[\mathrm{SC}\left(\mathrm{NH}_{2}\right)_{2}\right] \\
k_{2}=4.5 \mathrm{M}^{-1} \mathrm{~s}^{-1}\end{array}$ \\
\hline 3 & $\mathrm{NH}_{2}(\mathrm{NH}) \mathrm{CSSC}(\mathrm{NH}) \mathrm{NH}_{2}+\mathrm{H}_{2} \mathrm{O}_{2} \rightarrow 2 \mathrm{HOSC}(\mathrm{NH}) \mathrm{NH}_{2}$ & $\begin{array}{l}r_{3}=\mathrm{k}_{3}\left[\mathrm{H}_{2} \mathrm{O}_{2}\right]\left[\mathrm{NH}_{2}(\mathrm{NH}) \operatorname{CSSC}(\mathrm{NH}) \mathrm{NH}_{2}\right] \\
k_{3}=0.0058 \mathrm{M}^{-1} \mathrm{~s}^{-1}\end{array}$ \\
\hline 4 & $\mathrm{HOSC}(\mathrm{NH}) \mathrm{NH}_{2}+\mathrm{H}_{2} \mathrm{O}_{2} \rightarrow \mathrm{HO}_{2} \mathrm{SC}(\mathrm{NH}) \mathrm{NH}_{2}+\mathrm{H}_{2} \mathrm{O}$ & $\begin{array}{l}r_{4}=k_{4}\left[\mathrm{H}_{2} \mathrm{O}_{2}\right]\left[\mathrm{HOSC}(\mathrm{NH}) \mathrm{NH}_{2}\right] \\
k_{4}=0.022 \mathrm{M}^{-1} \mathrm{~s}^{-1}\end{array}$ \\
\hline 6 & $\mathrm{HO}_{3} \mathrm{SC}(\mathrm{NH}) \mathrm{NH}_{2}+\mathrm{H}_{2} \mathrm{O} \rightarrow \mathrm{HSO}_{3}{ }^{-}+\mathrm{OC}\left(\mathrm{NH}_{2}\right)_{2}+\mathrm{H}^{+}$ & $\begin{array}{l}r_{6}=k_{6}\left[\mathrm{HO}_{3} \mathrm{SC}(\mathrm{NH}) \mathrm{NH}_{2}\right] \\
k_{6}=6.8 \times 10^{-6} \mathrm{~s}^{-1}\end{array}$ \\
\hline 7 & $\mathrm{HSO}_{3}^{-}+\mathrm{H}_{2} \mathrm{O}_{2} \rightarrow \mathrm{SO}_{4}^{2-}+\mathrm{H}_{2} \mathrm{O}+\mathrm{H}^{+}$ & $\begin{array}{l}r_{7}=\left(7+1.48 \times 10^{7}\left[\mathrm{H}^{+}\right]\right)\left[\mathrm{H}_{2} \mathrm{O}_{2}\right]\left[\mathrm{HSO}_{3}{ }^{-}\right] \\
k_{7}=7+1.48 \times 10^{7}\left[\mathrm{H}^{+}\right]=4.68 \times 10^{5} \mathrm{M}^{-1} \mathrm{~s}^{-1}\end{array}$ \\
\hline 8 & $\mathrm{NH}_{2}(\mathrm{NH}) \mathrm{CSSC}(\mathrm{NH}) \mathrm{NH}_{2} \rightarrow \mathrm{SC}\left(\mathrm{NH}_{2}\right)_{2}+\mathrm{S}+$ other species & $\begin{array}{l}r_{8}=k_{8}\left[\mathrm{NH}_{2}(\mathrm{NH}) \mathrm{CSSC}(\mathrm{NH}) \mathrm{NH}_{2}\right] \\
k_{8}=5.67 \times 10^{-6} \mathrm{~s}^{-1}\end{array}$ \\
\hline
\end{tabular}

decreasing $[\mathrm{TU}]$ shows an inflection point, which suggests a reaction of the form $\mathrm{TU}_{2} \rightarrow$ TU. $\mathrm{TUO}_{3}$ appears after $\mathrm{TUO}_{2}$. The concentration of $\mathrm{TUO}_{2}$ decreases after reaching a maximum due to its further oxidation. In separate experiments, we found that $\mathrm{TUO}_{3}$ decomposition and oxidation by hydrogen peroxide have almost the same rate, which implies that the direct oxidation can be ignored. Figure 3 also shows that the corresponding curves simulated with the mechanism in Table 1 have all the experimental features. Only the rate constants for R2 and $\mathrm{R} 4$ have been fitted; we took $k_{3}, k_{5}$ and $k_{6}$ from a prior HPLC study ${ }^{14}$ and $k_{8}$ was determined from our experiments on $\mathrm{TU}_{2}$ hydrolysis, while $k_{1}$ and $k_{7}$ were obtained from Hoffmann ${ }^{15}$ and Rábai et al., ${ }^{16}$ respectively. Our value for $k_{2}$ differs significantly from the $3000 \mathrm{M}^{-1} \mathrm{~s}^{-1}$ reported by Epstein et al., ${ }^{2}$ who note that their model is quite insensitive to this value, but supports the determination of $k_{2}=10 \mathrm{M}^{-1} \mathrm{~s}^{-1}$ by Rábai et al. ${ }^{17}$

In summary, HPLC can directly identify such species as TU, $\mathrm{TU}_{2}, \mathrm{TUO}_{2}, \mathrm{TUO}_{3}$, though not the transient sufenyl acid $\left(\mathrm{HOSC}(\mathrm{NH}) \mathrm{NH}_{2}\right)$. It also provides real time tracking of multiple sulfur species during the oxidation of TU. Further investigations will extend this approach to other oxidants (chlorite, bromate, etc.) and other sulfur compounds (thiosulfate, thiocyanate, etc.). This method may make it possible to solve the longstanding

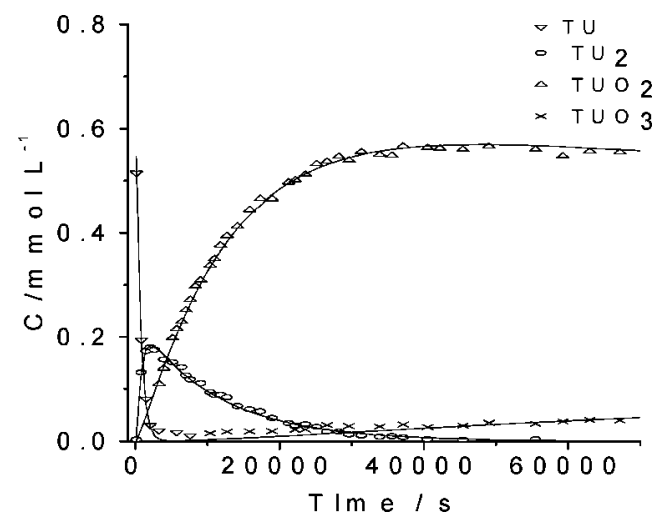

Figure 3. Measured time series (symbols) and simulated kinetic curves (lines) for the hydrogen peroxide-thiourea system. $\left[\mathrm{H}_{2} \mathrm{O}_{2}\right]_{0}=1.18 \times$ $10^{-2} \mathrm{M},[\mathrm{TU}]_{0}=6.2 \times 10^{-4} \mathrm{M}$; flow rate of mobile phase $=0.50$ $\min / \min , T=25{ }^{\circ} \mathrm{C}, \mathrm{pH}=1.50$. mechanistic problems of two-component oxyhalogen-sulfur reactions. ${ }^{2,3,18,19}$ The HPLC tracking of sulfur species also has potential applications in studying the antibiotic activity of physiological fluids ${ }^{20}$ and the desulfurization of fuel.

Acknowledgment. This work was supported by grant CHE0615507 from the U. S. National Science Foundation, Grant No. 20573134 from the National Science Foundation of China, Grant No. 20050290512 from the Ministry of Chinese Education and Grant No. BK2007037 of JSNSF. Q.G. is grateful for the financial support of the visiting program of the Chinese Scholarship Council.

\section{References and Notes}

(1) Wang, W.; Schuchmann, M. N.; Schuchmann, H.-P.; Knolle, W.; von Sonntag, J.; von Sonntag, C. J. Am. Chem. Soc. 1999, 121, 238. 5852 .

(2) Epstein, I. R.; Kustin, K.; Simoyi, R. H. J. Phys. Chem. 1992, 96,

(3) Simoyi, R. H.; Epstein, I. R.; Kustin, K. J. Phys. Chem. 1994, 98, 551.

(4) Sharma, V. K.; Rivera, W.; Joshi, V. N.; Millero, F. J.; O'Connor, D. Environ. Sci. Technol. 1999, 33, 2645.

(5) Alamgir, M.; Epstein, I. R. Int. J. Chem. Kinet. 1985, 17, 429.

(6) Simoyi, R. H. J. Phys. Chem. 1986, 90, 2802.

(7) Doona, C.J.; Blittersdorf, R.; Schneider, F.W. J. Phys. Chem. 1993 , 97, 7258 .

(8) Chinake, C.R.; Simoyi, R.H. J. Phys. Chem. 1994, 98, 4012.

(9) Svarovsky, S. A.; Simoyi, R. H.; Makarov, S. V. J. Phys. Chem. B 2001, 105, 12634.

169.

(11) Stirling, D. The Sulfur Problem: Cleaning Up in Industrial Feedstocks; Royal Society of Chemistry: Cambridge, U.K., 2000.

(12) Grigorova, B.; Wright, S. J. Chromatogr. 1986, 368, 444.

(13) Kim, K.; Lin, Y. T.; Mosher, H. S. Tetrahedron Lett. 1988, 29, 3183.

(14) Gao, Q.; Liu, B.; Li, L.; Wang, J. J. Phys. Chem. A 2007, 111, 872.

(15) Hoffmann, M.; Edwards, J. O. Inorg. Chem. 1977, 16, 3333.

(16) Rábai, G.; Kustin, K.; Epstein, I. R. J. Am. Chem. Soc. 1989, 111, 3870 .

(17) Rábai, G.; Wang, R.T.; Kustin, K. Int. J. Chem. Kinet. 1993, 25, 53.

(18) Chinake, C.R.; Mambo, E. J.; Simoyi, R.H. J. Phys. Chem. 1994, 98, 2908.

(19) Horváth, A. K.; Nagypál, I.; Peintler, G.; Epstein, I. R. J. Am. Chem. Soc. 2004, 126, 6246.

(20) Ashby, M. T.; Carlson, A. C.; Scott, M. J. J. Am. Chem. Soc. 2004, 126, 15976.

JP8003932 